Research Article

\title{
Application of Mathematical Modeling in Public Health Decision Making Pertaining to Control of COVID- I 9 Pandemic in India
}

\author{
Anil Kumar', Rupali Roy²
}

${ }^{1}$ Deputy Director General (Public Health), Directorate General of Health Services, Ministry of Health \& Family Welfare. ${ }^{2}$ Deputy Assistant Director General (Leprosy), Directorate General of Health Services, Ministry of Health \& Family Welfare. DOI: https://doi.org/10.24321/2455.7048.202013

\section{I $\quad \mathbf{N} \quad \mathbf{F}$}

\author{
Corresponding Author: \\ Rupali Roy, Directorate General of Health \\ Services, Ministry of Health \& Family Welfare. \\ E-mail Id: \\ dr.rupali@gov.in \\ Orcid Id: \\ https://orcid.org/0000-0002-7195-320X \\ How to cite this article: \\ Kumar A, Roy R. Application of Mathematical \\ Modeling in Public Health Decision Making \\ Pertaining to Control of COVID-19 Pandemic in \\ India. Epidem Int 2020; 5(2): 23-26. \\ Date of Submission: 2020-05-22 \\ Date of Acceptance: 2020-06-02
}

\section{$\begin{array}{llllllll}\mathbf{A} & \mathbf{B} & \mathbf{S} & \mathbf{T} & \mathbf{R} & \mathbf{A} & \mathbf{C} & \mathbf{T}\end{array}$}

Introduction: The COVID-19 is highly infectious and possibility of spread is more, it is expecting to see large number of cases in the coming days. There is need for effective public health measures at community level including those recommended for containment and buffer zones. To achieve this, there is need for evidence based decision making at all level. Mathematical modeling can be important tool to achieve this. The objective of this research article is to sensitize public health decision makers at Centre, State and District level about application of Mathematical Modeling in decision making for prevention and control of COVID-19.

Methodology: BAILEY'S MODEL was applied on secondary data for COVID -19. In this model, the removal rate is calculated which is the percentage of removed persons in the infected population. Further, regression analysis has been done, to show the linear relationship between the total infection rate and the total recovery rate. Linking of this model with decision making has been described.

Findings: BAILEY'S MODEL described that when the number of infected is equal to the number of removed patients, the coefficient will reach $100 \%$ threshold and the epidemic will be extinguished. In this article as per the Regression Analysis (Linear) of Bailey's Relative Removal Rate (BMRRR), COVID 19, India, it is observed that the trend reached to 100 in the month of mid of September, 2020. So it may be interpreted that at that point of time, the number of infected will be equal to the number of removed patients, and that's why the coefficient will reach $100 \%$ threshold.

Conclusion: This a very good model to support analysis and interpretation of State/District data (whenever numbers of cases are high) and it will also help in relevant decision making in control activities of COVID 19 Pandemic. This will further help government to take long-term disease prevention and intervention programs.

Keywords: Mathematical, COVID-19, Prevention, BAILEY'S, PublicHealth 


\section{Introduction}

In India, the numbers of COVID-19 positive cases are rising progressively and various standard mathematical and epidemiological models, regression and time series models are attempted to estimate the rising numbers. ${ }^{1-4} \mathrm{As}$ on $19^{\text {th }}$ May 2020, in India there were total 106475 cases, total 42306 cured \& discharged and 3302 deaths occurred. ${ }^{5}$ There is significance raise observed in $24 \mathrm{hrs}$, on $19^{\text {th }}$ May, 2020, the COVID-19 positive cases were around $6000 .{ }^{6}$ As COVID-19 is highly infectious and possibility of spread is more, it is expecting to see more number of cases per day in the coming days.

The direct and indirect cost in terms of illness and death is likely to be large. It is expected that with stronger public health system, ultimate preparation and as well as effective management of the public at large could have helped to reduce the large number of deaths because of this disease. ${ }^{7}$ Few established models tried to establish that, due to lack of herd immunity in the population and the highly contagious nature of the Corona virus, there is chance that about $2 / 3^{\text {rd }}$ of the population can be infected unless strong containment measures are timely take. ${ }^{8}$

At this hour, it is most important is to keep infections at manageable levels and ensure the effective surveillance system, complete tracing of contacts, adequate testing, isolation of patients, implement effectively all COVID care guidelines, and disseminate IEC. ${ }^{9}$ For India like country, the immediate requirement is to incorporate the visionary strategies to control the community spread. ${ }^{10}$

There is therefore need for effective public health measures at community level including those recommended for containment and buffer zones. To achieve this, there is need for evidence based decision making at Central, State and District level. Mathematical modeling can be important tool to achieve this. At the present scenario, application of Mathematical \& Statistical analysis has an essential role in linking the gap between the mathematical theory and public health practice for prevention and control of COVID-19. In addition, it should be promote the use of Mathematical model and statistical analyses to provide practical insight and support for the disease control and prevention. ${ }^{11}$

Application of Mathematical Modeling and statistical analyses about corona virus is to indicate what will be the situation if it is different circumstances. These models are not envisioned to predict fixed outcomes. That is why; the hour of need is to make meaningful interpretation of a surveillance data by applying mathematical model to have some logical understanding of the situation.

The objective of this research article is to sensitize public health decision makers at Centre, State and District level about application of Mathematical Modeling in decision making for prevention and control of COVID-19. In this article BAILEY'S MODEL ${ }^{12}$ is used to analyze the secondary data and its application for decision making. This is a chainbinomial type of the model and it is applicable for infection which has high infectivity and approximately constant incubation periods.

Norman Bailey is a brilliant mathematician who has described the model in his famous book, "The Mathematical Theory of Epidemics," which was the first edition of the present work. In 1953, he described the applications of many other fields in biology and medicine, the attempt to develop mathematical theories of epidemics exhibits the usual conflict between epidemiological data and realism. ${ }^{13}$

\section{Methodology}

In this article, secondary data for COVID -19 in India was collected from the website namely https://www. worldometers.info/coronavirus/country/india [5]. In the data sheet, the cumulative number of total COVID 19 cases in India since $1^{\text {st }}$ March 2020 to $19^{\text {th }}$ May 2020 along with total of cumulative recovered cases and cumulative deaths were entered.

In this article to analyze the COVID 19 virus spreading in India, the BAILEY'S MODEL is used and this model is applied after considered the distribution of the total size of a stochastic epidemic, involving both infection and removal. The model employed was of the 'continuous infection' type, according to which infected individuals continue as sources of infection until removed from circulation by recovery, death or isolation. The basic assumptions of the BAILEY'S MODEL is if $x$ is susceptible and $y$ infectious persons in circulation, the chance of one new infection taking place in time $d t$ is $\beta x y d t$, while the chance of a removal is Yydt, where, $\beta$ and $\gamma$ are the infection and removal rates, respectively. In this model, it is important to calculate the relative removal rate, i.e $\rho=\gamma / \beta$.

According to BAILEY's Model, the removal rate is calculated after calculating the percentage of removed persons in the infected population. Further, regression analysis has been done in the article, to get the results regarding relationship between the total infection rate and the total recovery rate.

Further in this article, it has been discussed as to how this model can be used at National, State and District level to support evidenced based decision making. This decision making may be vital to achieve early control of present pandemic utilizing available resources.

\section{Findings and Discussion}

The first three cases for COVID 19 were reported in India from Kerala on $30^{\text {th }}$ January 2020, however, they were not epidemiologically linked with other cases. Kerala later became COVID 19 free, before actual epidemic in India 
started. Actual epidemic in India started on $2^{\text {nd }}$ March and since then the number of confirmed case have been rising, the same can be seen in Figure 1. The graph is showing the day wise new COVID cases with reference to seven days moving average of doubling time.

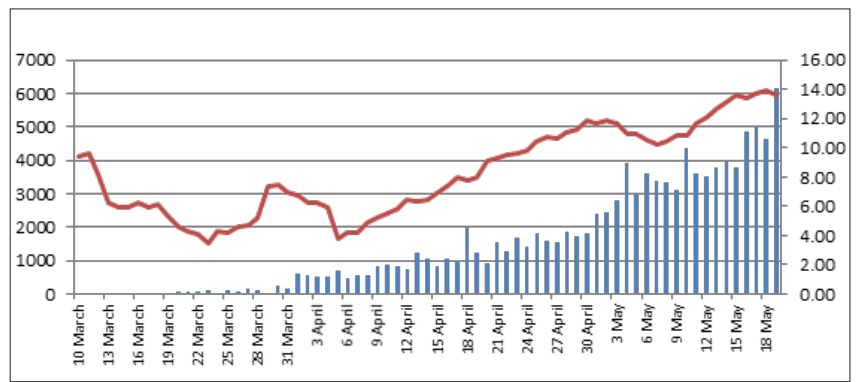

Figure I.Seven Days Moving Average of Doubling

Time and New COVID 19 Cases per Day, India

In the Figure 1, it is showing that on $19^{\text {th }}$ May 2020, in India, total 6147 cases were positive for COVID 19, whereas the cumulative number is 106475 and the 7 days moving average of doubling time is 13.5 .

In the graph below the numbers of cumulative cases since $1^{\text {st }}$ March 2020 to $19^{\text {th }}$ May 2020 are shown in blue color bar and the numbers of removed cases are shown in red color bar.

The line diagram in the same graph is showing the BAILEY's Model Relative Removal Rate (BMRRR). In the graph the BMRRR is reached to $42 \%$, it will further depend on how different control and preventive measures are being taken for COVID 19 in the country.

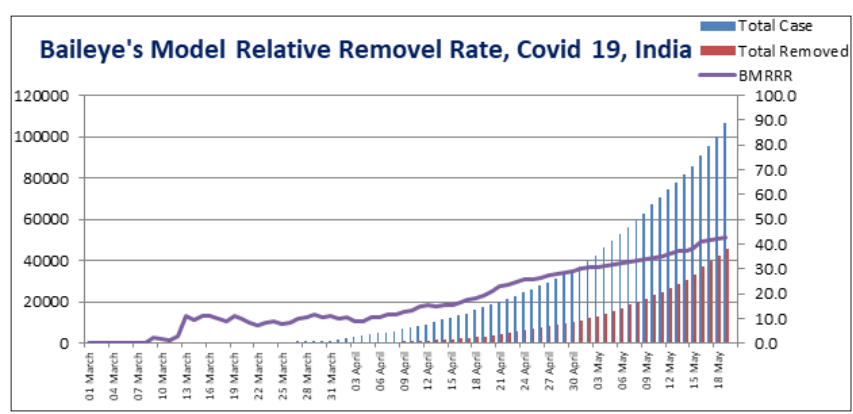

Figure 2.Bars showing the cumulative COVID- 19 cases from I ${ }^{\text {st }}$ March 2020 to I $^{\text {th }}$ May 2020 along with number of removed cumulative cases: the line diagram showing the change in BAILEY's Model Relative Removal Rate

Decrease in BAILEY's rate will indicate spread of virus in the community and reasons for the same need to be ascertained especially to find out whether there are issues related to implementation of public health measures. Important one to find out whether infection is spreading in newer areas previously unaffected. Increases in the rate may indicate successful implementation of public health measure and also introduction of better therapeutic options or introduction of vaccine.

According to this mathematical calculations, when the number of infected is equal to the number of removed patients, the coefficient will reach $100 \%$ threshold and the epidemic will be extinguished. That means the transmission of the virus has more or less stopped. Taking the rate to higher and higher level is reflection of moving forward in right direction and success of control measures being taken.

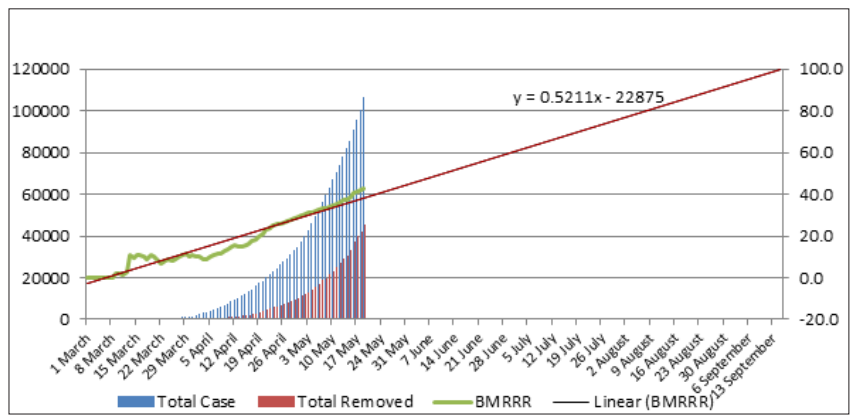

Figure 3.Regression Analysis (Linear) of Bailey's Relative Removal Rate, COVID 19, India

In the above graph, Regression Analysis (Linear) of Bailey's Relative Removal Rate (BMRRR), COVID 19, India has been done and it is showing that the linear line is reaching to 100 in the mid of September, 2020. So it may be interpreted that at that point of time the number of infected will be equal to the number of removed patients, and that's why the coefficient will reach $100 \%$ threshold.

However we must understand that this is a Stochastic model and outcome will depend on variance structure around it. There are two main stochasticity, demographic and environmental. ${ }^{14}$ So the decision makers must try to control and modify variables related to these two factors so that Bailey's Relative Removal Rate (BMRRR) continues to go up.

This can be an important tool in the hand of Central, State and District Authorities in decision-making and taking appropriate action at this time in the virus containment, epidemic situation management and control the pandemic spreading in the country. These predictions have farreaching consequences regarding how quickly and how strongly governments move to curb an Epidemic. ${ }^{15}$

Benefit of using this mathematical model is that it takes into consideration of various factors including spread of disease (field activities and other public health measures), clinical care/ recovery rate, effectiveness of any treatment/ vaccine which might be introduced later over a long period of time and not just short term fluctuations.

\section{Limitation}

This article is based on the collected secondary data for a 
specific period of time to fit and estimate the basic case number, infection rate, and recovery rate of COVID-19.

When we apply any mathematical model, we make some assumptions for a certain period of time, impact of few factors are being ignored such as population birth rate and natural mortality. Natural calamity, unpredictable population movement and important national or international events may have significant influence on this model. With the continuous release of epidemic data these important indicators may undergo significant changes in the spread of COVID-19 among the population.

\section{Conclusion}

The Prediction of the epidemic duration and size should be interpreted as applicable only to the confirmed cases based on the previous record. The issues regarding the accuracy, reliability and standard of reported data is complex and are beyond the scope of this work, which is more oriented on the mathematical modeling side. This is a simple model which can be utilized at Centre, State and District level for better epidemic situation management and control.

As per the guidelines of Govt. of India and various states, faculty of Community Medicine Department from various Medical College is supporting State/District Public Health Authority in data analysis and interpretation. This faculty can support analysis and interpretation of State/District data (whenever numbers of cases are high) by using this model and also help in interpretation and relevant decision making. This will further help government to take long-term disease prevention and intervention measures.

\section{Acknowledgement: None \\ Conflict of Interest: None}

\section{References}

1. Ndaïrou F, Area I, Nieto JJ, Torres DFM. Mathematical Modeling of COVID-19 Transmission Dynamics with a Case Study of Wuhan [published online ahead of print, 2020 Apr 27]. Chaos Solitons Fractals 2020; 109846. [DOI:10.1016/j.chaos.2020.109846].

2. Kumar S. Predication of Pandemic COVID-19 situation in Maharashtra, India. med Rxiv preprint. [DOI: https:// doi.org/10.1101/2020.04.10.20056697].

3. Currie CSM, Fowler JW, Kotiadis K, Monks T, Onggo BS, Robertson DA et al. How simulation modeling can help reduce the impact of COVID-19. [Published online 2020 Apr]. Journal of simulation 2020; 0:0, 1-9. [DOI: https://doi.org/10.1080/17477778.2020.1751570].

4. Available from: https://www.who.int.

5. Available from: https://www.worldometers.info/ coronavirus/country/india/

6. Available from: https://www.mohfw.gov.in.

7. Abraham T. Covid-19 in India: The Chronicle of a
Pandemic Foretold. The India Forum 2020; [Published online 2020 Apr 3]. https://www.theindiaforum.in/ article/covid-19-india.

8. Khanna RC, Cicinelli MV, Gilbert SS, Honavar SG, Murthy GVS. COVID-19 pandemic: Lessons learned and future directions. Indian Journal of Ophthalmology 2020; 68: 703-710.

9. Editorial. India under COVID-19 lockdown. The Lancet 2020; 395.

10. Krishnakumar B, Rana S. COVID 19 in India: Strategies to combat from combination threat of life and livelihood. Journal of Microbiology, Immunology and Infection 2020; March [published online, 2020 March]. https:// doi.org/10.1016/j.jmii.2020.03.024.

11. Gondauri D, Mikautadze E, Batiashvili M. Research on COVID-19 Virus Spreading Statistics based on the Examples of the Cases from Different Countries. Electron J Gen Med 2020; 17(4): em209.

12. Bailey NTJ. Maximum Likelihood Estimation of the Relative Removal Rate from the Distribution of the Total Size of an Intra-Household Epidemic. J Hyg (Lond) 1954; 52(3): 400-402.

13. Bailey NTJ. The Simulation of Stochastic Epidemics in two dimensions. Proceedings of the Fifth Berkeley Symposium on Mathematical Statistics and Probability. University of California of Press 1967; 1: 666. https:// projecteuclid.org/euclid.bsmsp/1200512974.

14. Choisy M, Guégan JF, Rohani P. Mathematical Modeling of Infectious Diseases Dynamics. Encyclopedia of Infectious Diseases: Modern Methodologies 2007; 22: 380-409.

15. Jewell NP, Lewnard JA, Jewell BL. Predictive Mathematical Models of the COVID-19 Pandemic Underlying Principles and Value of Projections. JAMA 2020; 323(19): 1893-1894. 